\title{
Inducing the attachment of cable bacteria on oxidizing electrodes
}

\author{
Cheng Li, Clare E. Reimers, and Yvan Alleau \\ College of Earth, Ocean and Atmospheric Sciences, Oregon State University, Corvallis, Oregon 97331, USA
}

Correspondence: Cheng Li (cheng.li@oregonstate.edu)

Received: 22 August 2019 - Discussion started: 2 September 2019

Revised: 17 December 2019 - Accepted: 14 January 2020 - Published: 6 February 2020

\begin{abstract}
Cable bacteria (CB) are multicellular, filamentous bacteria within the family of Desulfobulbaceae that transfer electrons longitudinally from cell to cell to couple sulfide oxidation and oxygen reduction in surficial aquatic sediments. In the present study, electrochemical reactors that contain natural sediments are introduced as a tool for investigating the growth of CB on electrodes poised at an oxidizing potential. Our experiments utilized sediments from Yaquina Bay, Oregon, USA, and we include new phylogenetic analyses of separated filaments to confirm that CB from this marine location cluster with the genus "Candidatus Electrothrix". These $\mathrm{CB}$ may belong to a distinctive lineage, however, because their filaments contain smaller cells and a lower number of longitudinal ridges compared to cables described from other locales. The results of a $135 \mathrm{~d}$ bioelectrochemical reactor experiment confirmed that these CB can migrate out of reducing sediments and grow on oxidatively poised electrodes suspended in anaerobic seawater. CB filaments and several other morphologies of Desulfobulbaceae cells were observed by scanning electron microscopy and fluorescence in situ hybridization on electrode surfaces, albeit in low densities and often obscured by mineral precipitation. These findings provide new information to suggest what kinds of conditions will induce $\mathrm{CB}$ to perform electron donation to an electrode surface, further informing future experiments to culture $\mathrm{CB}$ outside of a sediment matrix.
\end{abstract}

\section{Introduction}

Long-distance electron transfer (LDET) is a mechanism used by certain microorganisms to generate energy through the transfer of electrons over distances greater than a celllength. These microorganisms may pass electrons across dissolved redox shuttles, nanofiber-like cell appendages, outer- membrane cytochromes, and/or mineral nanoparticles to connect extracellular electron donors and acceptors ( $\mathrm{Li}$ et al., 2017; Lovley, 2016). Recently, a novel type of LDET exhibited by filamentous bacteria in the family of Desulfobulbaceae was discovered in the uppermost centimeters of various aquatic, but mainly marine, sediments (Malkin et al., 2014; Trojan et al., 2016). These filamentous bacteria, also known as "cable bacteria" (CB), electrically connect two spatially separated redox half reactions and generate electrical current over distances that can extend to centimeters, which is an order of magnitude longer than previously recognized LDET distances (Meysman, 2017).

The unique ability of CB to perform LDET creates a spatial separation of oxygen reduction in oxic surface layers of organic-rich sediment from sulfide oxidation in subsurface layers (Meysman, 2017). The spatial separation of these two half reactions also creates localized porewater $\mathrm{pH}$ extremes in oxic and sulfidic layers, which induces a series of secondary reactions that stimulate the geochemical cycling of elements such as iron, manganese, calcium, phosphorus, and nitrogen (Kessler et al., 2018; Rao et al., 2016; Seitaj et al., 2015; Sulu-Gambari et al., 2016a, b). In addition to altering established perceptions of sedimentary biogeochemical cycling and microbial ecology (Meysman, 2017; Nielsen and Risgaard-Petersen, 2015), CB also possess intriguing structural features that may inspire new engineering applications in areas of bioenergy harvesting and biomaterial design (Lovley, 2016; Meysman et al., 2019).

Much is still unknown about the basic mechanism(s) that $\mathrm{CB}$ use to perform LDET. It has been suggested that when long filaments form, a chain of cells at the sulfidic terminal catalyzes anodic half reactions (e.g., $0.5 \mathrm{H}_{2} \mathrm{~S}+$ $\left.2 \mathrm{H}_{2} \mathrm{O} \rightarrow 0.5 \mathrm{SO}_{4}^{2-}+4 \mathrm{e}^{-}+5 \mathrm{H}^{+}\right)$, while a cathodic half reaction $\left(\mathrm{O}_{2}+4 \mathrm{e}^{-}+4 \mathrm{H}^{+} \rightarrow 2 \mathrm{H}_{2} \mathrm{O}\right)$ is completed by cells at the oxic terminal. Electron transfer then occurs along the lon- 
gitudinal ridges of CB filaments via electron hopping promoted by extracellular cytochromes positioned within a redox gradient or via conductive electronic structures such as pili (Bjerg et al., 2018; Cornelissen et al., 2018; Kjeldsen et al., 2019; Meysman et al., 2019; Pfeffer et al., 2012). These hypotheses await further verification, and CB remain uncultured and difficult to grow outside of sediment. This difficulty complicates efforts to study them using different techniques, such as electrochemical assays and metatranscriptomics.

In a previous benthic microbial fuel cell (BMFC) experiment in a marine estuary (Reimers et al., 2017), we serendipitously observed the attachment of CB to carbon fibers serving as an anode in an anaerobic environment above sediments. This finding suggested that $\mathrm{CB}$ possess the ability to donate electrons to solid electron acceptors, and it indicated a range of cathodic potentials favorable for electron transfer (Reimers et al., 2017). However further investigations are still needed to study the conditions that allow the attachment of CB to a poised electrode and to document electron transfer mechanisms at their cathodic terminus. In the present study, we first clarify the phylogenetic placement of $\mathrm{CB}$ found in sediments from Yaquina Bay, Oregon, where the BMFC was previously deployed. Then, we describe the design of a bioelectrochemical reactor configured to mimic the environment in the anodic chamber of a BMFC and verify conditions that can induce CB attachment on electrodes. Results assert that when oxygen is not available, CB can glide through sediments and seawater to an electrode poised at oxidative potentials. Thus, the present study provides new information about the chemotaxis of CB in environments other than sediments, revealing key conditions for their attachment to surfaces and growth in both natural and engineered environments.

\section{Materials and methods}

\subsection{Study site and sediment collection}

Several studies suggest that CB may be found widely in coastal sediments possessing high rates of sulfide generation coupled with organic matter mineralization (Larsen et al., 2015; Malkin et al., 2014; Pfeffer et al., 2012). Therefore, to initiate this enquiry, sediment with these two characteristics was collected from Yaquina Bay, Oregon, USA, using a hand shovel at a site on an intertidal mud flat (IMF, $44^{\circ} 37^{\prime} 30 \mathrm{~N}, 124^{\circ} 00^{\prime} 26 \mathrm{~W}$ ). The IMF site is located about $3 \mathrm{~km}$ upstream from the site where the BMFC was deployed in the abovementioned study (Reimers et al., 2017). The top $20 \mathrm{~cm}$ of these sediments were sieved through a $0.5 \mathrm{~mm}$ mesh size metal screen to remove macrofauna and shell debris. Then the sieved sediments were allowed to settle and stored in sealed buckets in a cold room at $5{ }^{\circ} \mathrm{C}$.

\subsection{Sediment incubation}

To cultivate CB of Yaquina Bay, IMF sediment was initially incubated for $60 \mathrm{~d}$. These first incubations were started $2 \mathrm{~d}$ after collection and performed after homogenizing the sieved sediments under a flow of $\mathrm{N}_{2}$ and then packing the sediment into triplicate polycarbonate tubes $(15 \mathrm{~cm}$ height and $9.5 \mathrm{~cm}$ inner diameter). These cores were submerged in an aquarium containing aerated seawater collected from Yaquina Bay and held at $15^{\circ} \mathrm{C}$, a temperature that is about average for the mudflats of Yaquina Bay (Johnson, 1980). Once a distinctive suboxic layer was evident from color changes in the top centimeters of the cores, profiles of porewater $\mathrm{pH}, \mathrm{O}_{2}$, and $\mathrm{H}_{2} \mathrm{~S}$ were measured to $2-3 \mathrm{~cm}$ depth with commercial microelectrodes (Unisense A.S., Aarhus, Denmark) to confirm geochemical evidence of $\mathrm{CB}$ activity (see below). Multiple small sub-cores $(0.5 \mathrm{~cm}$ diameter, $3 \mathrm{~cm}$ in length) were then taken out from each incubated core using cut-off syringes. Some of these sediment plugs were washed gently to reduce the volume of fine particles, and CB biomass was further separated out from the sediment matrix by using custom-made tiny glass hooks following Malkin et al. (2014). Sediment plugs and separated filamentous biomass were frozen or fixed for subsequent phylogenetic and microscopic characterizations.

\subsection{Reactor configuration and operation}

To mimic the conditions where $\mathrm{CB}$ were found attached to electrode fibers in a BMFC (Reimers et al., 2017), a bioelectrochemical reactor was assembled from a polycarbonate core tube $(15 \mathrm{~cm}$ height and $11.5 \mathrm{~cm}$ inner diameter, Fig. 1) as a second phase of this research. A lid, a center rod to locate and support the electrodes, and a perforated bottom partition were made from polyvinyl chloride (PVC, McMaster-Carr, Elmhurst, IL). Three carbon brush electrodes, which would serve as two anodes and a control electrode (Mill-Rose, Mentor, $\mathrm{OH}, 2 \mathrm{~cm}$ in diameter and $8.9 \mathrm{~cm}$ total length), were inserted through septa within holes in the core lining to meet the center rod and were spaced radially at $120^{\circ}$ angles from each other.

To initiate the experiment, the reactor was placed inside an $8 \mathrm{~L}$ plastic beaker (with perforated walls) containing $3 \mathrm{~cm}$ of IMF sediments at the bottom. Enough additional IMF sediment was then placed inside the reactor to form an $8 \mathrm{~cm}$ thick layer after settling and compacting. In this configuration, the sediment-water interface was approximately $1 \mathrm{~cm}$ away from the lower extent of the carbon brush electrodes. The beaker was then gently lowered inside an aquarium filled with Yaquina Bay seawater until fully submerged, and the reactor was left uncapped. Seawater in the aquarium was maintained at $15{ }^{\circ} \mathrm{C}$ and bubbled to maintain air saturation. A fuel cell circuit was completed by placing a $10 \mathrm{~cm}$ long carbonfiber brush cathode (Hasvold et al., 1997) and a reference electrode $(\mathrm{Ag} / \mathrm{AgCl}$ [3 M KCl], MI-401F, Microelectrodes, 
(a)
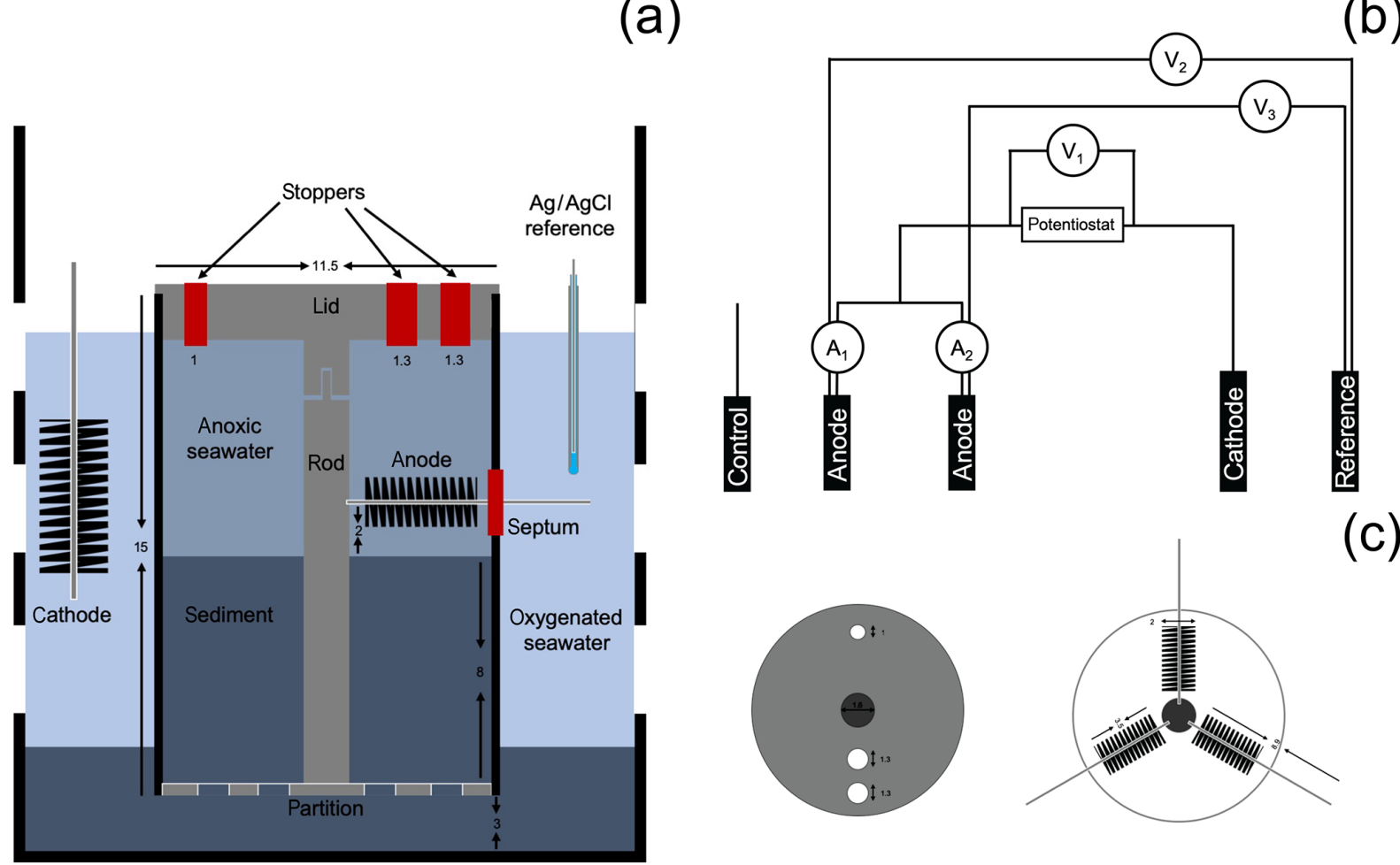

Figure 1. Schematic of the bioelectrochemical reactor design used in this study: (a) lateral view of the reactor, (b) electrical circuit of the reactor, and (c) bird's-eye view of the reactor cap and electrode arrangement. Dimensions are in cm. $A_{1}$ and $A_{2}$ represent the current monitored in duplicate anodes, $V_{1}$ represents the potential monitored between the duplicate anodes and cathode, and $V_{2}$ and $V_{3}$ represent potentials monitored between the duplicate anodes and the reference electrode.

Inc., Bedford, $\mathrm{NH}$ ) into the seawater outside the reactor tube (Fig. 1a).

The reactor was monitored in an open-circuit state for $31 \mathrm{~d}$ to allow the development of a CB population within the top centimeters of sediment as had been observed in the previous incubations. Microelectrode profiling was used to characterize the vertical distribution of porewater $\mathrm{pH}$ and concentrations of $\mathrm{O}_{2}$ and $\mathrm{H}_{2} \mathrm{~S}$ on day 13 and 24 of reactor incubation. On day 31 , carbon fiber samples were trimmed off the unpoised anode brushes as initial reference samples, and the reactor was sealed to create fully anoxic conditions. Beginning on day 44, under seal, cathode versus anode potentials were poised at $300 \mathrm{mV}$ by regulating two of the three anode carbon brushes with an individual custom-designed potentiostat circuit board (NW Metasystems, Bainbridge Island, WA) (Fig. 1b). The third brush was kept at open circuit as a continuing control. Electrode potentials of the anode (versus reference) and whole cell and the current flow between anodes and cathode were monitored and recorded every $7 \mathrm{~min}$ with a multichannel data logger (Agilent Technologies, Santa Clara, CA, model 34970A fitted with two 34901A multiplexer modules) wired to the potentiostat outputs. The electrodes were poised for more than 3 months. On day $48 \mathrm{mi}-$ croelectrode profiling was repeated by lowering the sensors through the ports in the reactor lid (Fig. 1c). The pH microelectrode was broken at the start of this profile and therefore no $\mathrm{pH}$ or calculated total sulfide are reported (only $\mathrm{H}_{2} \mathrm{~S}$ ). On day 135, the anodes and control electrode were extracted through the side openings in the bioreactor tube for SEM (scanning electron microscopy) and CARD-FISH (catalyzed reporter deposition-fluorescence in situ hybridization) analyses (described below). At the experiment's end, the final $\mathrm{pH}$ of the seawater inside of the anodic chamber was measured by microelectrode (see below).

\subsection{Microelectrode measurements}

The sediments incubated in open cores and in the bioelectrochemical reactor were each profiled with $\mathrm{O}_{2}, \mathrm{pH}$, and $\mathrm{H}_{2} \mathrm{~S}$ microelectrodes to show through geochemical signatures evidence of CB activity (Malkin et al., 2014). Microelectrodes had tip diameters of $100 \mu \mathrm{m}$. The $\mathrm{O}_{2}$ microelectrodes were calibrated in air-purged seawater (as $100 \%$ air saturation) and in a solution of sodium ascorbate and $\mathrm{NaOH}$ (both to a final concentration of $0.1 \mathrm{M}$, as $0 \% \mathrm{O}_{2}$ saturation). Vertical oxygen microprofiles were recorded starting from $2 \mathrm{~mm}$ above either the sediment-water interface or in the reactor above the carbon brush, at a step size of $400 \mu \mathrm{m}$. Vertical $\mathrm{pH}$ and $\mathrm{H}_{2} \mathrm{~S}$ microprofiles were measured concurrently at 
the same spatial interval. The $\mathrm{pH}$ microelectrode was calibrated by using standard $\mathrm{pH} 4,7$, and 10 buffer solutions (Ricca Chemical, Arlington, Texas, USA). $\mathrm{H}_{2} \mathrm{~S}$ microelectrodes were calibrated by generating an 11-point calibration relationship by standard addition, from 0 to $7.48 \mu \mathrm{M} \mathrm{H}_{2} \mathrm{~S}$ at $\mathrm{pH}=1.6$. A $3 \mathrm{mM}$ standard solution was made from crystal $\mathrm{Na}_{2} \mathrm{~S}_{9} \mathrm{H}_{2} \mathrm{O}$ (>98.0\%, MilliporeSigma, Burlington, MA) in an anoxic glove box. Total sulfide concentration at each profile depth was derived from $\mathrm{pH}$ and $\mathrm{H}_{2} \mathrm{~S}$ according to equilibrium relationships given in Millero et al. (1988).

\subsection{SEM}

To confirm the presence of $\mathrm{CB}$ and to examine the characteristic longitudinal ridges and cell-cell junctions of $\mathrm{CB}$, filaments extracted from the sediments and carbon fibers from the reactor electrodes were visualized by scanning electron microscopy (SEM). Samples were dehydrated in a graded series of ethanol solutions from $10 \%$ to $100 \%$. Specimens were then mounted on aluminum SEM stubs with doublesided carbon tape, critical-point dried using an EMS 850 Critical Point Dryer, and sputter-coated with gold and palladium using a Cressington 108 sputter coater. The resultant specimens were observed under a FEI Quanta 600FEG ESEM at 5-15 kV. This instrument also provided elemental spectra by X-Ray Energy Dispersive Spectrometry (EDS).

\subsection{CARD-FISH}

Catalyzed reporter deposition-fluorescence in situ hybridization (CARD-FISH) was used to microscopically identify Desulfobulbaceae filaments using a Desulfobulbaceaespecific oligonucleotide probe (DSB706; 5'-ACC CGT ATT CCT CCC GAT-3') labeled with horseradish peroxidase (Lücker et al., 2007). In preparation for CARD-FISH, sediment samples were fixed with a $1: 1$ (vol: vol) ethanol and phosphate-buffered saline solution and stored at $-20^{\circ} \mathrm{C}$ until analysis. Extracted bacterial filaments and carbon fibers cut from the carbon brush electrodes were treated with a fixative solution containing $1.25 \%$ glutaraldehyde and $1.3 \%$ osmium tetroxide. Fixed samples were stored at $-20^{\circ} \mathrm{C}$ until analysis. Sediment and bacterial filament samples were first retained on polycarbonate membrane filters and then mounted onto a glass slide by using $0.2 \%$ agarose (Malkin et al., 2014). Carbon fiber samples were mounted directly onto a glass slide without first retaining on a filter. Mounted samples were sequentially permeabilized by $10 \mathrm{mg} \mathrm{mL}^{-1}$ of lysosome $\left(2 \mathrm{~h}\right.$ at $\left.37^{\circ} \mathrm{C}\right)$ and achromopeptidase $(1 \mathrm{~h}$ at $37^{\circ} \mathrm{C}$ ). After permeabilization, glass slides were incubated in $\mathrm{H}_{2} \mathrm{O}_{2}(0.15 \%$ in methanol) for $30 \mathrm{~min}$ at room temperature $\left(\sim 25^{\circ} \mathrm{C}\right)$ to inactivate the endogenous peroxidases. The hybridization process was performed in a standard hybridization buffer at $46^{\circ} \mathrm{C}$ with $45 \%$ formamide for $7 \mathrm{~h}$ (Wendeberg, 2010). Alexa Fluro 488 (ThermoFisher, Waltham, Mas- sachusetts, USA) was deposited on samples in the presence of $0.15 \% \mathrm{H}_{2} \mathrm{O}_{2}$.

Two-color CARD-FISH was performed on some carbon fiber samples to look for a previously observed cooccurrence of CB and other electroactive bacteria on electrode surfaces (Reimers et al., 2017). To perform the CARDFISH, horseradish peroxidases on the hybridized DSB706 probes were inactivated by $0.15 \% \mathrm{H}_{2} \mathrm{O}_{2}$. The inactivated samples were then hybridized with a Desulfuromonadalesspecific oligonucleotide probe (DRM432; 5'-CTT CCC CTC TGA CAG AGC-3') modified with horseradish peroxidase in standard hybridization buffer at $46^{\circ} \mathrm{C}$ with $40 \%$ formamide for $5 \mathrm{~h}$ and sequentially stained with Alexa Fluro 555 (ThermoFisher, Waltham, Massachusetts, USA). A counter stain, 4',6-diamidino-2-phenylindole (DAPI), was applied to all samples after the deposition of fluorescent probe(s). Hybridization samples were visualized using confocal laser scanning microscopy (CLSM) (LSM 780, Zeiss, Jena, Germany).

\subsection{Microbial community characterizations}

To investigate the phylogeny of the $\mathrm{CB}$ discovered in Yaquina Bay, genomic DNA was extracted from three sediment plug samples and from two separated filamentous biomass samples using a MoBio PowerSoil DNA Extraction Kit. To avoid insufficient cell lysis, all samples went through five to seven freeze-thaw cycles before the use of the extraction kit (Roose-Amsaleg et al., 2001). Bacterial 16S rRNA genes were amplified by polymerase chain reaction (PCR) with random primers $357 \mathrm{wF}\left(5^{\prime}\right.$-CCTACGGGNGGCWGCAG-3') and 785R (5'GACTACHVGGGTATCTAATCC-3'). Amplification and sequencing of DNA (Illumina MiSeq Reagent Kit v3, $2 \times$ $300 \mathrm{bp}$ ) was performed by the Center of Genome Research and Biocomputing at Oregon State University. Sequences were processed using DADA2 (v.1.10) in R (3.5.0), as described in a previous study (Callahan et al., 2016). Sequences were aligned to the Silva SSU Ref NR database (v.132) and clustered into operational taxonomic units (OTUs) at $97 \%$ similarity. Representative sequences classified into the family of Desulfobulbaceae were tagged and aligned to $16 \mathrm{~S}$ rRNA gene sequences from previously identified CB (Trojan et al., 2016). A phylogenetic tree was constructed using RaxML with 1000 bootstraps (Stamatakis, 2014). Sequences from this study were deposited to the Genbank's Sequence Read Archive (MK388690-MK388723, PRJNA587126).

\section{Results and discussion}

\subsection{Cable bacteria activity in the sediments of Yaquina Bay}

During the initial open incubations of IMF sediment, the top centimeter of each core changed from dark to light gray, and 
(a) Oxygen $\left(\mu \mathrm{mol} \mathrm{L}^{-1}\right)$

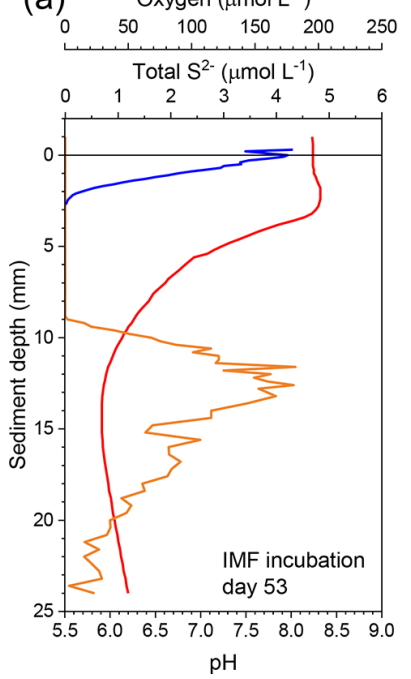

(b) Oxygen $\left(\mu \mathrm{mol} \mathrm{L}^{-1}\right)$
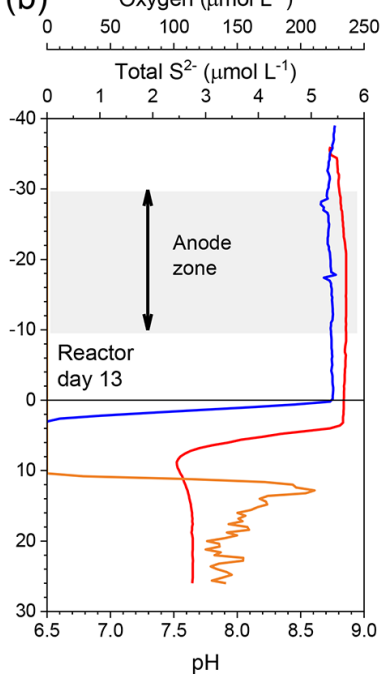

(c)
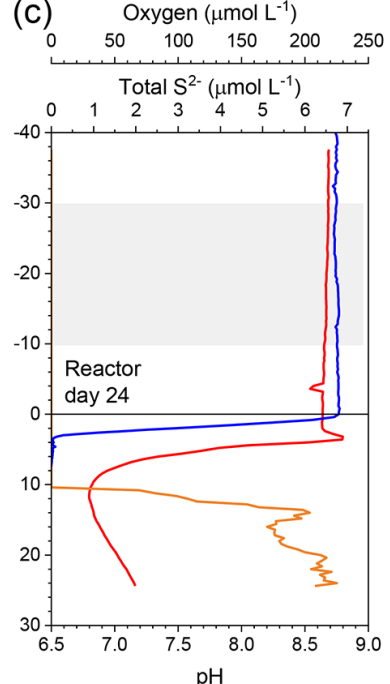

(d) Oxygen $\left(\mu \mathrm{mol} \mathrm{L} \mathrm{L}^{-1}\right)$
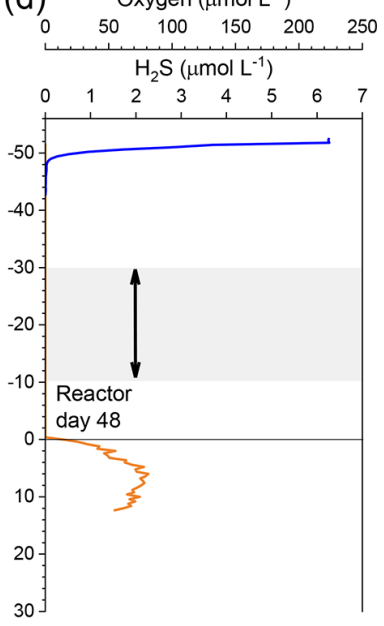

Figure 2. Representative microelectrode depth profiles of oxygen (blue), $\mathrm{pH}$ (red), and $\Sigma \mathrm{H}_{2} \mathrm{~S}$ or $\mathrm{H}_{2} \mathrm{~S}$ (yellow) in (a) IMF sediment after $53 \mathrm{~d}$ of incubation and in the bioelectrochemical reactor at (b) day 13, (c) day 24, and (d) day 48.

a brownish layer formed from the sediment-water interface to $\sim 0.2 \mathrm{~cm}$ depth. Hallmarks of the activity of CB were documented by microelectrode profiling after $53 \mathrm{~d}$ of culture. These hallmarks were a sulfide-free suboxic zone and opposing $\mathrm{pH}$ extremes at approximately $0.2 \mathrm{~cm}$ and $1-1.5 \mathrm{~cm}$ deep (Fig. 2a). Although a faint smell of sulfide was detected during collection of the sediment, total sulfide concentrations detected by microelectrode profiling were low compared to previous studies of marine sediments hosting CB (Malkin et al., 2014). The $\mathrm{pH}$ minimum within the anoxic layers of cultured sediment was 6.0, indicating acidification coupled to sulfide or iron sulfide oxidation.

SEM revealed that cells within extracted filaments were 0.5 to $1.2 \mu \mathrm{m}$ wide and 2 to $3 \mu \mathrm{m}$ long (Fig. 3a, b, c). Typical morphological features of $\mathrm{CB}$ including longitudinal ridges and cell-cell junctions were observed, though a smaller number of ridges (8-10) were usually spotted compared to 1658 in other characterizations (Malkin et al., 2014). Certain filaments extracted from sediments were covered by heterogeneous coatings of mineral particles as was observed recently by Geerlings et al. (2019) (Fig. 3c). These particles have similar elemental compositions to some authigenic clays (Burdige, 2006), showing enrichments of silicon, aluminum, magnesium, and iron. In our open incubation samples, some thinner filaments were also seen that displayed no obvious longitudinal ridges, although cell-cell junctions were still visible (Fig. 3b). Extracted filaments reacted positively to the DSB 706 probe and DAPI (Figs. 3d and S1 in the Supplement).

When analyzing the 16S rRNA gene sequence data, we found that one of the candidate CB genera, "Candidatus Electrothrix", was relatively abundant in sediment plug samples $(2.9 \%)$ and predominant $(83.5 \%)$ in separated filamen- tous biomass samples. The most abundant Desulfobulbaceae OTUs within these samples were aligned with a previously established taxonomy framework of CB (Trojan et al., 2016) (Fig. 3e). Partial 16s rRNA sequences of CB have been discovered in sediment samples from the US East Coast, Gulf of Mexico, and certain sites on the US West Coast from SILVA or GenBank databases (Trojan et al., 2016). Our studies have provided the first combined microscopic and genetic observations of $\mathrm{CB}$ in sediments from the northeastern Pacific coast of the United States, reinforcing the suggestion that CB bacteria are distributed globally. This result also indicates that Yaquina Bay, OR, where we deployed the BMFC, indeed harbors a rich population of $\mathrm{CB}$.

\subsection{Encouraging the growth of cable bacteria on poised electrodes}

Geochemical hallmarks of CB developed within 2 weeks of culture within the bioelectrochemical reactor (Fig. 2b). The $\mathrm{pH}$ minimum within the sulfidic layer and the $\mathrm{pH}$ maximum in the oxic layer of sediment became more extreme by day 24 (Fig. 2c), indicating that a CB population was actively mediating electrogenic sulfide oxidation and transporting electrons to reduce oxygen. After sealing the reactor, oxygen concentration in the overlaying seawater dropped below detection limits and the open-circuit anode potential fell to $-104 \mathrm{mV}$ (versus $\mathrm{Ag} / \mathrm{AgCl}$ ). Once poised with the potentiostat, the cathode and anode potentials became stable at approximately 330 and $30 \mathrm{mV}$ versus $\mathrm{Ag} / \mathrm{AgCl}$, respectively. When microelectrode profiling was performed on day 48, the measurements indicated that the overlying seawater was anoxic (except right below the sample port) and that free $\mathrm{H}_{2} \mathrm{~S}$ was detectable right below the sediment-water interface but not in the water column (Fig. 2d). The pH of the seawater 

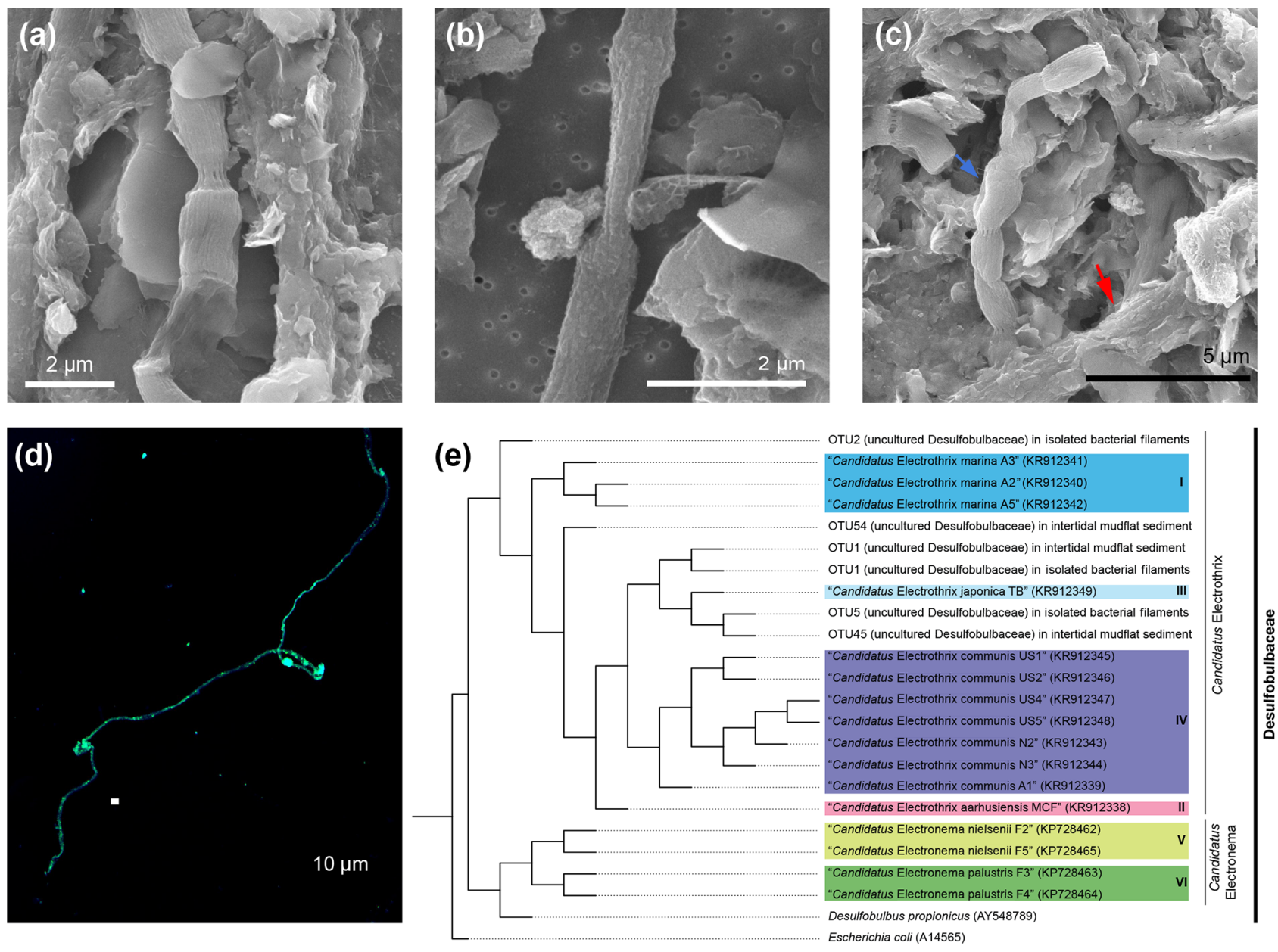

$\overline{0.5}$

Figure 3. Cable bacteria filaments recovered from Yaquina Bay sediments. (a) A cable bacteria filament under SEM. (b) A thin type of cable bacteria filament under SEM. (c) Multiple filaments of cable bacteria clumped together under SEM. The blue arrow indicates a section of cable, and the red arrow indicates a cable bacteria filament covered with a mineral coating. (d) Identification of the filaments belonging to Desulfobulbaceae using catalyzed reporter deposition-fluorescence in situ hybridization (DSB 706 probe + Alexa Fluor 488 in green and DSB DAPI in blue). (e) Phylogenetic tree of Desulfobulbaceae 16s rRNA gene sequences recovered from IMF sediment and extracted biomass samples. Color boxes indicate previously recognized species of cable bacteria. The scale bar shows $5 \%$ sequence divergence.

measured inside of the reactor chamber at the experiment's end was 6.2 , consistent with sulfide oxidation under anaerobic conditions within the anolyte seawater. Current collection started to increase once the anodic potential became stable, indicating that the anode brushes were being used as an electron acceptor. Current records collected from duplicate electrodes were similar, and the current in each steadily increased to $\sim 30.5 \pm 2.5 \mu \mathrm{A}$ by day 86 , stabilized, then rose again to a peak of $\sim 75 \pm 8 \mu \mathrm{A}$ on day 101 . After this maximum, current decreased and restabilized at $\sim 30 \pm 5 \mu \mathrm{A}$. These electrochemical results are portrayed in Fig. 4. The cause of the current rise and subsequent fall (Fig. 4) is unknown but is a common occurrence in marine BMFC experiments (Nielsen et al., 2009; Ryckelynck et al., 2005). It is likely that such behavior is a result of a varying supply of reductants from the underlying sediment, changes in the anodic biofilm, and finally loss of anode surface area due to mineral deposition induced by microbial activity and/or the applied electrical potential. Coatings containing iron, phosphorus, sulfur, silicon, and aluminum are often found on anode surfaces of BMFCs in marine environments and were seen by SEM in the present study (see below). Cyclic voltammetry (CV, Fig. S2a) performed on the anode brushes at day 52 and 100 yielded broad and poorly defined electrochemical signals. The interpretation of such voltammograms may be complicated by a high uncompensated resistance between working electrode and reference electrode (Babauta and Beyenal, 2015). While an oxidation peak can be clearly identified at potentials near where the anode was held, the peak current did not increase with an increase in scan rate (Fig. S2b). The 


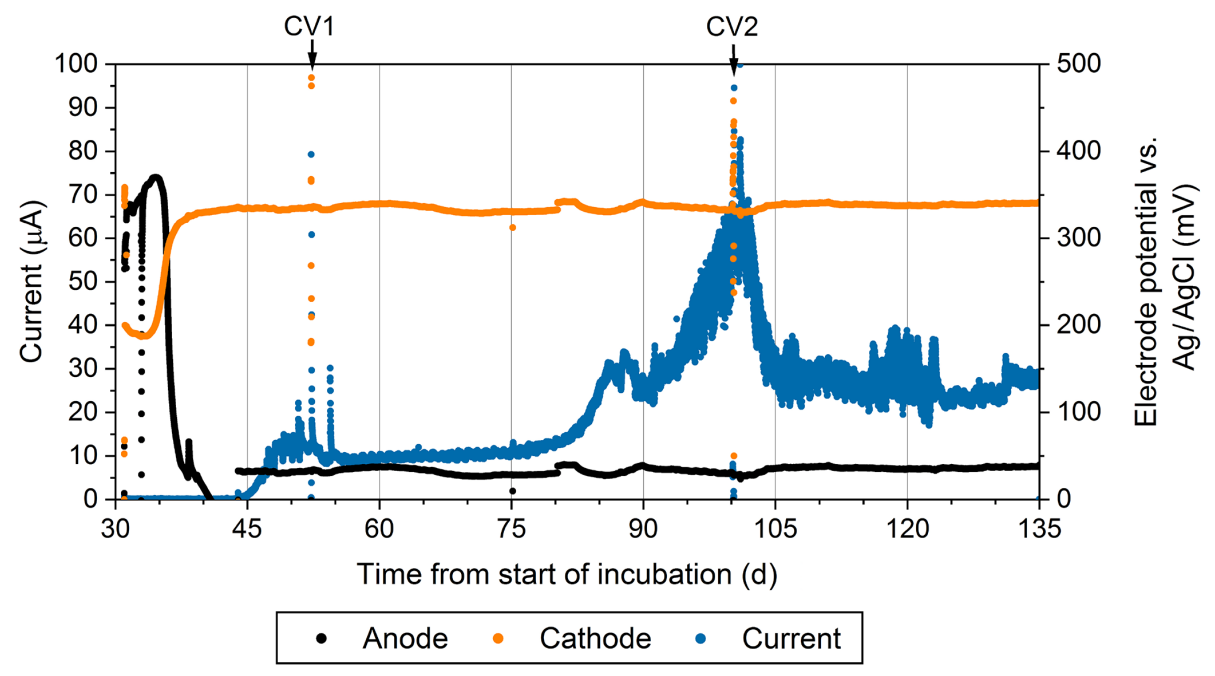

Figure 4. The current production (blue), the anodic potential (black), and cathodic potential (orange) over time during the reactor experiment. The reference electrode was an $\mathrm{Ag} / \mathrm{AgCl}$ electrode with a saturated $\mathrm{KCl}$ filling solution. This figure only shows measurements associated with one of the duplicate electrodes.

peak oxidation current also did not change much between day 52 and day 100 . This CV behavior suggests that any current generated by the biomass of electroactive bacteria, including $\mathrm{CB}$, was obscured during scans by current arising from irreversible redox reactions, such as oxidation of dissolved iron. A reduction peak was unidentifiable throughout the scans, a common phenomenon in sediment MFCs (Babauta and Beyenal, 2015). Taken together, these results demonstrate that the electrode surface was altered during the course of the bioreactor experiment by mineral and chemical precipitate deposition (Imran et al., 2019).

\subsection{Examining the attachment of cable bacteria on the anode}

The hypothesis that led to the bioreactor experiments in this study was that an electrode poised at an oxidative potential can produce redox conditions and geochemical gradients that attract $\mathrm{CB}$ and that will lead to their electron donation to an electrode. Several observations that were made on harvested electrodes affirm this hypothesis. Firstly, under SEM, bacteria filaments with visible longitudinal ridges and cell-cell junctions were found integrated into biofilms on the surfaces of poised electrodes (Fig. 5a, b). As observed in the initial IMF sediment examinations, filaments appeared to contain a smaller number of ridges ( 8 to 10 ) compared to previously reported CB filaments and others were without pronounced ridges along their longitudinal axes. The latter examples did show cell-cell junctions and appeared to have wrinkled surfaces (Fig. 5c, d, e, f). Secondly, many of the bacteria filaments observed on the electrode surfaces were encrusted, suggesting mineral deposition similar to that observed at the oxic terminal of CB filaments in sediments (Fig. $5 \mathrm{~g}, \mathrm{~h}$ ). EDS indicated that these deposits contained iron, phospho- rus, oxygen, and silicon (Fig. S3b). The control electrode that was not positively poised displayed no mineral deposition and nearly no cell growth (Fig. 5i). Thirdly, most of the bacterial filaments on the poised electrode surfaces reacted positively with the Desulfobulbaceae-specific probe. CARDFISH performed in the present study revealed that the anodic carbon fibers harbored many short bacterial filaments, as well as colonies belonging to the family of Desulfobulbaceae (Fig. 6a, b, c, d, e, f). Clear cell-cell junctions were observed along many of the fluorescent filaments. However, the complexity of the carbon fiber samples often hampered clear microscopic visualization of fluorescent cells. Application of an additional Desulfuromonadales-specific oligonucleotide probe (DRM432) confirmed the presence of other known electrogenic bacteria on the carbon fibers near Desulfobulbaceae cells as well (Fig. 6b, c, d).

Though a global occurrence has recently been indicated (Malkin et al., 2014), CB successfully evaded microbiological survey for quite a long time. One of the reasons is likely that the phylogeny of CB is overshadowed by the broad family of Desulfobulbaceae, which are often highly abundant in marine sediments (Kuever, 2014). Another reason may be a resistance of the cells of $\mathrm{CB}$ to routine cell lysing techniques that have been used with many DNA extraction kits (Trojan et al., 2016). Therefore, their identification in various studies has relied on microscopic observations of their unique filamentous form and morphological features (ridges and cell-cell junctions), combined with fluorescence in situ hybridization labeling (Malkin et al., 2014, 2017; Malkin and Meysman, 2015). The electrochemical reactor in this study was anoxic for more than $100 \mathrm{~d}$. The observation of CB on the anodic carbon fibers at the end of this experiment confirms that, although they may not have been abundant, they 


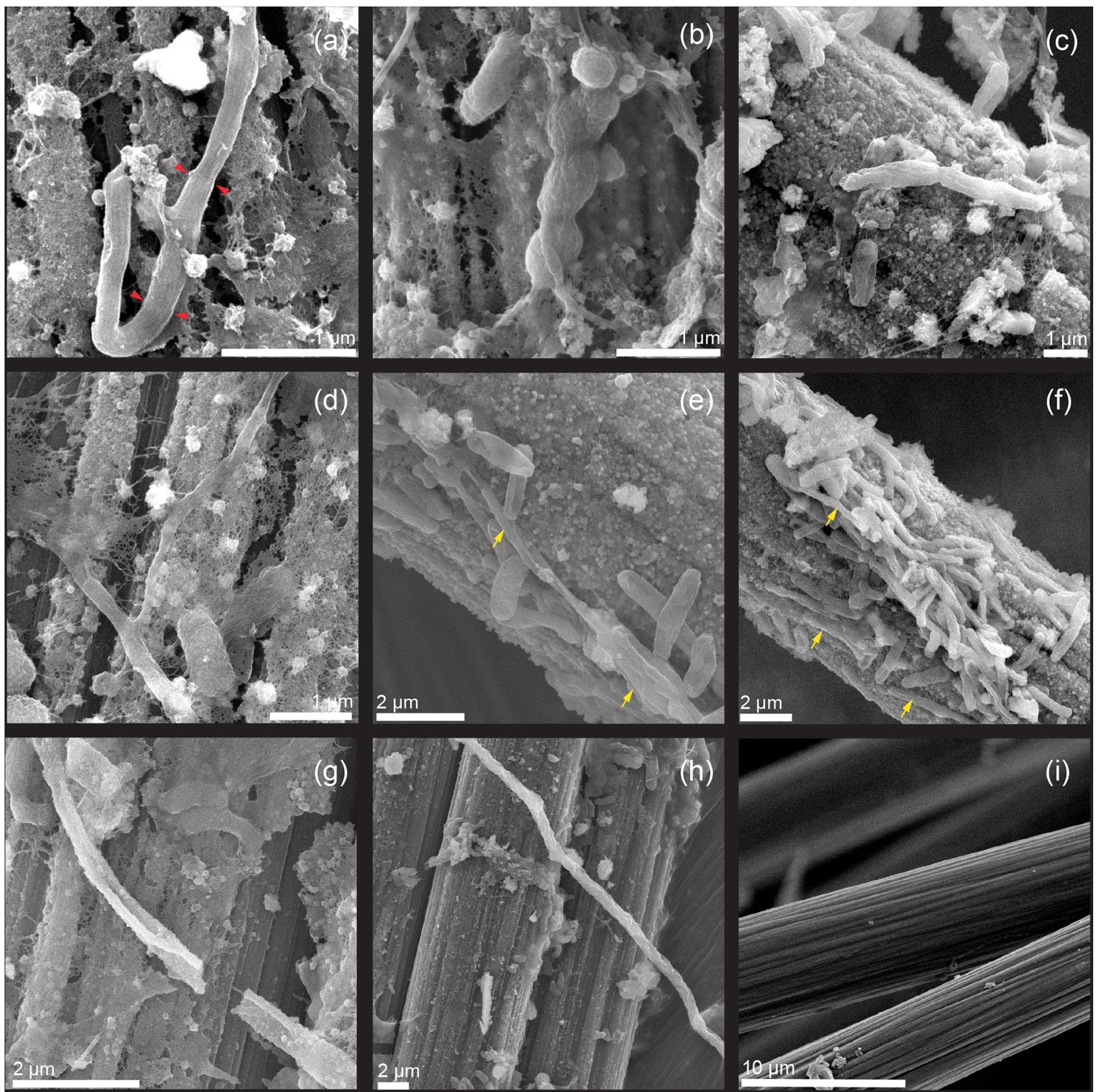

Figure 5. SEM images illustrating (a, b) cable bacteria filaments with visible ridges and cell-cell junctions incorporated into the biofilms on carbon fiber electrode surfaces. Red pointers indicate cell-cell junctions. (c, d, e, f) Short bacterial filaments without typical morphological features of cable bacteria. Yellow arrows indicate the locations of elongated cells. (g, h) Mineral-encrusted bacterial filaments. (i) Image of control electrode surface after culture.

can survive under such conditions and were likely using the anode as an electron acceptor (as suggested previously by Reimers et al., 2017). Besides the recognized forms of CB, short filaments within the family of Desulfobulbaceae that possessed different morphologies were also observed on the anode surface. Aller et al. (2019) suggest that redox environment may play an important role in controlling the length of $\mathrm{CB}$ filaments. For example, in the bioturbated zone as- sociated with the tube worm Chaetopterus variopedatus, in which redox conditions often oscillated between oxic and hypoxic, $\mathrm{CB}$ were present predominately in short filaments. Assuming the $\mathrm{CB}$ can use an electrode as an electron acceptor, the distance between the electron donor and acceptor utilized by $\mathrm{CB}$ may be short, reducing the advantage of forming long filaments. 


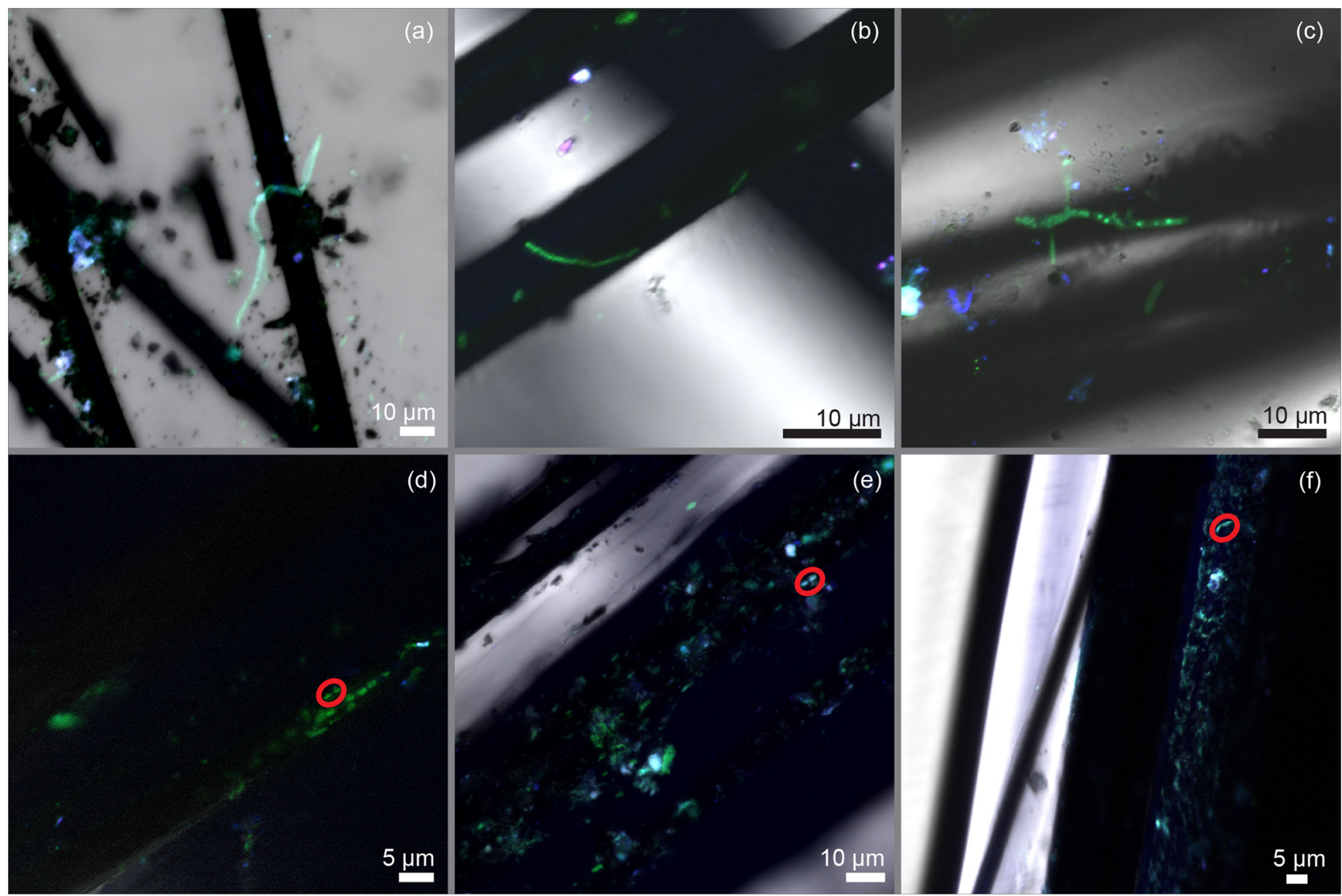

Figure 6. (a-c) Confocal microscope images illustrating cable bacteria filaments on the carbon fibers that served as an anode. (d-f) Colonies of cells belonging to Desulfobulbaceae. Red circles indicate a possible doublet of the long cells. Cells were visualized using catalyzed reporter deposition-fluorescence in situ hybridization (DSB 706 probe + Alexa Fluor 488, green; DRM 432 + Alexa Fluor 555, red; and DAPI, blue).

The closest culturable relative to CB, Desulfobulbus propionicus, can utilize an electrode as an electron acceptor to oxidize $\mathrm{S}^{0}, \mathrm{H}_{2}$, and organic acids like pyruvate, lactate, and propionate (Holmes et al., 2004). While CB appear to possess features like motility and an ability to form loops and bundles that are similar to large sulfur bacteria (but distinct from the $D$. propionicus), our SEM and CARD-FISH examinations suggest that $\mathrm{CB}$ on oxidative electrode surfaces may produce extracellular structures to transfer electrons to an electrode and/or to insoluble Fe(III)-oxides similar to D. propionicus (Bjerg et al., 2016; Holmes et al., 2004; Jørgensen, 2010; Pfeffer et al., 2012). Admittedly, indisputable proof of electron transfer from CB to electrodes still awaits growth in purer biofilms and cultures.

\section{Summary and implications for the electrode-associated growth of cable bacteria}

The present study introduces bioelectrochemical reactors as an approach to investigate filamentous cable bacteria and their unique ability to transfer electrons. Furthermore, we confirm that an active population of filamentous $\mathrm{CB}$ are present in Yaquina Bay, Oregon, USA, where CB were previously found attached to carbon-fiber electrode surfaces within a BMFC (Reimers et al., 2017). Moreover, by incubating intertidal sediment collected from Yaquina Bay in a reactor mimicking the anodic chamber of a BMFC, we observed that $\mathrm{CB}$ can be drawn to electrodes at oxidative electrical potentials. Thus, we have further evidence that $\mathrm{CB}$ can survive under anoxic conditions in the presence of an oxidative electrode serving as an electron acceptor. The bioelectrochemical reactor study also showed attachment of CB to an oxidative electrode when the surrounding seawater was stripped of hydrogen sulfide and at a $\mathrm{pH} \sim 6.2$. However, the observed CB density and the overall density of recognizable cells were both relatively low on electrode surfaces, as the respirable surface area appeared to become limited by the deposition of mineral coatings. More work is needed to determine conditions or experimental designs that may attract $\mathrm{CB}$ to an electrode while not also leading to excessive mineral precipitation on electrode surfaces. Developing ex situ culture techniques of $\mathrm{CB}$ and using these approaches to 
gain insight into their electron transfer will contribute to the overall understanding of this group of bacteria, their genomic makeup, and their survival in both natural and engineered environments.

Data availability. Partial 16S rRNA gene and raw sequences are deposited in the Genbank's Sequence Read Archive (MK388690MK388723, PRJNA587126).

Supplement. The supplement related to this article is available online at: https://doi.org/10.5194/bg-17-597-2020-supplement.

Author contributions. CL and CER conceived the study. YA designed and assembled the bioelectrochemical reactor. CL performed the microscopic examinations and microprofiling and analyzed the microbial community and phylogenies. CL also wrote the manuscript, with major rewrites and editing contributed by CER.

Competing interests. The authors declare that they have no conflict of interest.

Acknowledgements. This research was funded through grant N00014-17-1-2599 from the Office of Naval Research to Clare E. Reimers. We thank Teresa Sawyer, the Electron Microscopy Facility Instrument Manager at Oregon State University, for assistance with the SEM imaging and Anne-Marie Girard for valuable advice on the confocal microscope imaging. The authors wish to acknowledge the Confocal Microscopy Facility of the Center for Genome Research and Biocomputing at Oregon State University, which is supported in part by an award (no. 1337774) from the National Science Foundation. We also thank our lab members for providing critical comments on the manuscript.

Financial support. This research has been supported by the Office of Naval Research (grant no. N00014-17-1-2599) and the National Science Foundation (grant no. 1337774).

Review statement. This paper was edited by Jack Middelburg and reviewed by two anonymous referees.

\section{References}

Aller, R. C., Aller, J. J., Zhu, Q., Heilbrun, C., Klingensmith, I., and Kaushik, A.: Worm tubes as conduits for the electrogenic microbial grid in marine sediments, Sci. Adv., 5, eaaw3651, https://doi.org/10.1126/sciadv.aaw3651, 2019.

Babauta, J. T. and Beyenal, H.: Introduction to electrochemically active biofilms, in Biofilms in Bioelectrochemical Systems: From Laboratory Practice to Data Interpretations, John Wiley \& Sons, Hoboken, NJ, USA, 1-35, 2015.
Bjerg, J. T., Damgaard, L. R., Holm, S. A., Schramm, A., and Nielsen, L. P.: Motility of electric cable bacteria, Appl. Environ. Microbiol., 82, 3816-3821, 2016.

Bjerg, J. T., Boschker, H. T. S., Larsen, S., Berry, D., Schmid, M., Millo, D., Tataru, P., Meysman, F. J. R., Wagner, M., Nielsen, L. P., and Schramm, A.: Long-distance electron transport in individual, living cable bacteria, P. Natl. Acad. Sci. USA, 115, 57665791, https://doi.org/10.1073/pnas.1800367115, 2018.

Burdige, D. J.: The components of marine sediments, in Geochemistry of Marine Sediments, Princeton University Press, Princeton, NJ, USA, 5-24, 2006.

Callahan, B. J., McMurdie, P. J., Rosen, M. J., Han, A. W., Johnson, A. J. A., and Holmes, S. P.: DADA2: high-resolution sample inference from Illumina amplicon data, Nat. Methods, 13, 581583, 2016.

Cornelissen, R., Bøggild, A., Thiruvallur Eachambadi, R., Koning, R. I., Kremer, A., Hidalgo-Martinez, S., Zetsche, E.-M., Damgaard, L. R., Bonné, R., Drijkoningen, J., Geelhoed, J. S., Boesen, T., Boschker, H. T. S., Valcke, R., Geerlings, N. M. J., Zetsche, E.-M., Hidalgo Martinez, S., Middelburg, J. J., and Meysman, F. J. R.: Mineral formation induced by cable bacteria performing long-distance electron transport in marine sediments, Biogeosciences, 16, 811-829, https://doi.org/10.5194/bg16-811-2019, 2019.

Geerlings, N. M. J., Zetsche, E.-M., Hidalgo Martinez, S., Middelburg, J. J., and Meysman, F. J. R.: Mineral formation induced by cable bacteria performing long-distance electron transport in marine sediments, Biogeosciences, 16, 811-829, https://doi.org/10.5194/bg-16-811-2019, 2019.

Hasvold, Ø., Henriksen, H., Melvir, E., Citi, G., Johansen, B. Ø., Kjønigsen, T., and Galetti, R.: Sea-water battery for subsea control systems, J. Power Sources, 65, 253-261, https://doi.org/10.1016/S0378-7753(97)02477-4, 1997.

Holmes, D. E., Bond, D. R., and Lovley, D. R.: Electron transfer by Desulfobulbus propionicus to $\mathrm{Fe}(\mathrm{III})$ and graphite electrodes, Appl. Environ. Microbiol., 70, 1234-1237, https://doi.org/10.1128/AEM.70.2.1234-1237.2004, 2004.

Imran, M., Prakash, O., Pushkar, P., Mungray, A., Kailasa, S. K., Chongdar, S., and Mungray, A. K.: Performance enhancement of benthic microbial fuel cell by cerium coated electrodes, Electrochim. Acta, 295, 58-66, https://doi.org/10.1016/J.ELECTACTA.2018.08.158, 2019.

Johnson, J. K.: Effects of temperature and salinity on production and hatching of dormant eggs of Acartia californiensis (Copepoda) in an Oregon estuary, Fish. Bull., 77, 567-584, 1980.

Jørgensen, B. B.: Big sulfur bacteria, ISME J., 4, 1083, https://doi.org/10.1038/ismej.2010.106, 2010.

Kessler, A. J., Wawryk, M., Marzocchi, U., Roberts, K. L., Wong, W. W., Risgaard-Petersen, N., Meysman, F. J. R., Glud, R. N., and Cook, P. L. M.: Cable bacteria promote DNRA through iron sulfide dissolution, Limnol. Oceanogr., 64, 1228-1238, https://doi.org/10.1002/lno.11110, 2018.

Kjeldsen, K. U., Schreiber, L., Thorup, C. A., Boesen, T., Bjerg, J. T., Yang, T., Dueholm, M. S., Larsen, S., Risgaard-Petersen, N., Nierychlo, M., Schmid, M., Bøggild, A., van de Vossenberg, J., Geelhoed, J. S., Meysman, F. J. R., Wagner, M., Nielsen, P. H., Nielsen, L. P., and Schramm, A.: On the evolution and physiology of cable bacteria, P. Natl. Acad. Sci. USA, 116, 1911619125, https://doi.org/10.1073/pnas.1903514116, 2019. 
Kuever, J.: The Family Desulfobulbaceae, in: The Prokaryotes: Deltaproteobacteria and Epsilonproteobacteria, edited by: Rosenberg, E., DeLong, E. F., Lory, S., Stackebrandt, E., and Thompson, F., Springer Berlin Heidelberg, Berlin, Heidelberg, 75-86, 2014.

Larsen, S., Nielsen, L. P., and Schramm, A.: Cable bacteria associated with long-distance electron transport in New England salt marsh sediment, Environ. Microbiol. Rep., 7, 175-179, https://doi.org/10.1111/1758-2229.12216, 2015.

Li, C., Lesnik, K. L., and Liu, H.: Stay connected: electrical conductivity of microbial aggregates, Biotechnol. Adv., 35, 669-680, https://doi.org/10.1016/j.biotechadv.2017.07.010, 2017.

Lovley, D. R.: Happy together: microbial communities that hook up to swap electrons, ISME J., 11, 327-336, https://doi.org/10.1038/ismej.2016.136, 2016.

Lücker, S., Steger, D., Kjeldsen, K. U., MacGregor, B. J., Wagner, M., and Loy, A.: Improved 16S rRNA-targeted probe set for analysis of sulfate-reducing bacteria by fluorescence in situ hybridization, J. Microbiol. Methods, 69, 523-528, doi10.1016/j.mimet.2007.02.009, 2007.

Malkin, S. Y. and Meysman, F. J. R.: Rapid redox signal transmission by "cable bacteria" beneath a photosynthetic biofilm, Appl. Environ. Microbiol., 81, 948-956, https://doi.org/10.1128/AEM.02682-14, 2015.

Malkin, S. Y., Rao, A. M. F., Seitaj, D., and Vasquez-Cardenas, D.: Natural occurrence of microbial sulphur oxidation by longrange electron transport in the seafloor, ISME J., 8, 1843-1854, https://doi.org/10.1038/ismej.2014.41, 2014.

Malkin, S. Y., Seitaj, D., Burdorf, L. D. W., Nieuwhof, S., Hidalgo-Martinez, S., Tramper, A., Geeraert, N., De Stigter, H., and Meysman, F. J. R.: Electrogenic sulfur oxidation by cable bacteria in bivalve reef sediments, Front. Mar. Sci., 4, https://doi.org/10.3389/fmars.2017.00028, 2017.

Meysman, F. J. R.: Cable bacteria take a new breath using long-distance electricity, Trends Microbiol., 26, 411-422, https://doi.org/10.1016/j.tim.2017.10.011, 2017.

Meysman, F. J. R., Cornelissen, R., Trashin, S., Bonné, R., Martinez, S. H., van der Veen, J., Blom, C. J., Karman, C., Hou, J.-L., Eachambadi, R. T., Geelhoed, J. S., Wael, K. De, Beaumont, H. J. E., Cleuren, B., Valcke, R., van der Zant, H. S. J., Boschker, H. T. S., and Manca, J. V: A highly conductive fibre network enables centimetre-scale electron transport in multicellular cable bacteria, Nat. Commun., 10, 4120, https://doi.org/10.1038/s41467019-12115-7, 2019.

Millero, F. J., Plese, T., and Fernandez, M.: The dissociation of hydrogen sulfide in seawater, Limnol. Oceanogr., 33, 269-274, https://doi.org/10.4319/lo.1988.33.2.0269, 1988.

Nielsen, L. P. and Risgaard-Petersen, N.: Rethinking sediment biogeochemistry after the discovery of electric currents, Ann. Rev. Mar. Sci., 7, 425-442, https://doi.org/10.1146/annurev-marine010814-015708, 2015.

Nielsen, M. E., Wu, D. M., Girguis, P. R., and Reimers, C. E.: Influence of substrate on electron transfer mechanisms in chambered benthic microbial fuel cells, Environ. Sci. Technol., 43, 86718677, https://doi.org/10.1021/es9013773, 2009.
Pfeffer, C., Larsen, S., Song, J., Dong, M., Besenbacher, F., Meyer, R. L., Kjeldsen, K. U., Schreiber, L., Gorby, Y. A., El-Naggar, M. Y., Leung, K. M., Schramm, A., RisgaardPetersen, N., and Nielsen, L. P.: Filamentous bacteria transport electrons over centimetre distances, Nature, 491, 218-221, https://doi.org/10.1038/nature11586, 2012.

Rao, A. M. F., Malkin, S. Y., Hidalgo-Martinez, S., and Meysman, F. J. R.: The impact of electrogenic sulfide oxidation on elemental cycling and solute fluxes in coastal sediment, Geochim. Cosmochim. Ac., 172, 265-286, https://doi.org/10.1016/j.gca.2015.09.014, 2016.

Reimers, C. E., Li, C., Graw, M. F., Schrader, P. S., and Wolf, M.: The identification of cable bacteria attached to the anode of a benthic microbial fuel cell: evidence of long distance extracellular electron transport to electrodes, Front. Microbiol., 8, 2055, https://doi.org/10.3389/fmicb.2017.02055, 2017.

Roose-Amsaleg, C., Garnier-Sillam, E., and Harry, M.: Extraction and purification of microbial DNA from soil and sediment samples, Appl. Soil Ecol., 18, 47-60, https://doi.org/10.1016/S09291393(01)00149-4, 2001.

Ryckelynck, N., Stecher III, H. A., and Reimers, C. E.: Understanding the anodic mechanism of a seafloor fuel cell: interactions between geochemistry and microbial activity, Biogeochemistry, 76, 113-139, https://doi.org/10.1007/s10533-005-2671-3, 2005.

Seitaj, D., Schauer, R., Sulu-Gambari, F., Hidalgo-Martinez, S., Malkin, S. Y., Burdorf, L. D. W., Slomp, C. P., and Meysman, F. J. R.: Cable bacteria generate a firewall against euxinia in seasonally hypoxic basins, P. Natl. Acad. Sci. USA, 112, 13278-13283, https://doi.org/10.1073/pnas.1510152112, 2015.

Stamatakis, A.: RAxML version 8: a tool for phylogenetic analysis and post-analysis of large phylogenies, Bioinformatics, 30, 1312-1313, https://doi.org/10.1093/bioinformatics/btu033, 2014.

Sulu-Gambari, F., Seitaj, D., Meysman, F. J. R., Schauer, R., Polerecky, L., and Slomp, C. P.: Cable bacteria control iron-phosphorus dynamics in sediments of a coastal hypoxic basin, Environ. Sci. Technol., 50, 1227-1233, https://doi.org/10.1021/acs.est.5b04369, 2016a.

Sulu-Gambari, F., Seitaj, D., Behrends, T., Banerjee, D., Meysman, F. J. R., and Slomp, C. P.: Impact of cable bacteria on sedimentary iron and manganese dynamics in a seasonallyhypoxic marine basin, Geochim. Cosmochim. Ac., 192, 49-69, https://doi.org/10.1016/j.gca.2016.07.028, 2016b.

Trojan, D., Schreiber, L., Bjerg, J. T., Bøggild, A., Yang, T., Kjeldsen, K. U., and Schramm, A.: A taxonomic framework for cable bacteria and proposal of the candidate genera Electrothrix and Electronema, Syst. Appl. Microbiol., 39, 297-306, https://doi.org/10.1016/j.syapm.2016.05.006, 2016.

Wendeberg, A.: Fluorescence in situ hybridization for the identification of environmental microbes, Cold Spring Harb. Protoc., https://doi.org/10.1101/pdb.prot5366, 2010. 